\title{
PROSPECTS OF REFLEXOTHERAPY IN THE TREATMENT OF GASTROINTESTINAL SYMPTOMS IN PATIENTS WITH DIABETES
}

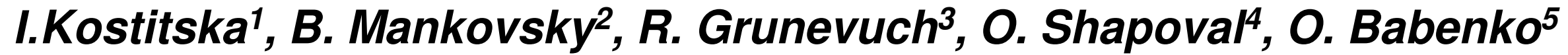

1'Ivano-Frankivsk National Medical University, Endocrinology, Ivano-Frankivsk, Ukraine

${ }^{2}$ Shupyk National Medical Academy of Postgraduate Education, Diabetology, Kyiv, Ukraine

${ }^{3}$ Ivano-Frankivsk National Medical University, General Practice Family Practice- Physical Rehabilitation and Sports Medicine, Ivano-Frankivsk, Ukraine

${ }^{4}$ Ivano-Frankivsk NationalMedical University, Internal Medicine No.1- Immunopathology and Allergology named after academician Neiko Ye. M.,

Ivano-Frankivsk, Ukraine

${ }^{5}$ Ivano-Frankivsk National Medical University, Internal Medicine No.1- Immunopathology and Allergology named after academician Neiko Ye. M.,

Ivano-Frankivsk, Ukraine

\section{Background}

Gastroparesis is considered as one on the severest manifestations of

autonomic neuropathy on the background of diabetes mellitus (DM); it is diagnosed too late as its symptoms are often considered as the manifestations

of other diseases of the gastrointestinal tract. Asymptomatic diabetic gastroparesis (DG) is considered as one of many predictors of labile DM and at the onset of the symptoms, the number of hospitalizations and treatment

costs increase while the average life expectancy decreases significantly.
Aim
The aim of this study was to compare the effectiveness of Itopride hydrochloride and acupuncture for the treatment of DG. Acupuncture may improve gastrointestinal

symptoms in patients with various disorders, but its efficacy in DG is unclear.

\section{Method}

We studied 36 patients with DG who were randomly allocated into 2 groups: first group diabetics with symptoms of gastroparesis received itopride hydrochloride (daily doses - $150 \mathrm{mg}$ ) for 3 weeks and second group patients with confirmed diagnosis of DG assigned to 10 sessions of laser acupuncture treatments during 20 minutes 5 times per week.

Gastric emptying rate, glucose and glycated haemoglobin $\left(\mathrm{HbA}_{1} \mathrm{C}\right)$ levels were measured at start and end of each treatment period. The patients completed the Gastroparesis Cardinal Symptom Index (GCSI). No subjects studied have had the signs of other disorders of dysfunction in gastrointestinal motility.

\begin{tabular}{|c|c|c|}
\hline \multicolumn{3}{|c|}{ Baseline characteristics } \\
\hline & First group $(n=18)$ & Second group $(n=18)$ \\
\hline Gender (M/F) & $8 / 10$ & $7 / 11$ \\
\hline Age, years & $44.7 \pm 4.4$ & $52.2 \pm 4.3$ \\
\hline Duration of diabetes, years & $12.8 \pm 3.2$ & $13.0 \pm 4.1$ \\
\hline$H b A_{1} C, \%$ & $8.3 \pm 2.1$ & $8.6 \pm 2.3$ \\
\hline Fasting plasma glucose, $\mathrm{mmol} / \mathrm{L}$ & $7.8 \pm 0.6$ & $7.2 \pm 0.9$ \\
\hline Postprandial glycemia, $\mathrm{mmol} / \mathrm{L}$ & $9.9 \pm 0.3$ & $9.8 \pm 0.7$ \\
\hline Mean GCSI score & $26.4 \pm 1.5$ & $25.9 \pm 1.8$ \\
\hline${ }^{13} \mathrm{C}$-octanoic breath test, $\min$ & $96.4 \pm 9.7$ & $128.2 \pm 3.2$ \\
\hline
\end{tabular}

\section{Results}

We have found a direct correlation between the GCSI total score and the results of the ${ }^{13} C$-OBT $(r=0.87 \pm 0.04, p<0.05)$, which indicated the need to widely use questionnaires with the aim of early diagnosis of

DG symptoms. The most pronounced changes were as follows: the absence of nausea in $47.2 \%$ of cases $(p<0.05)$; the incidence of vomiting decreased by $29.4 \%(\mathrm{p}<0.05)$; a feeling of fullness after eating decreased by $14.8 \%(p<0.05)$; the incidence of

flatulence decreased by $18.1 \%(p<0.05)$ in all patients.

Laser acupuncture was associated with a decrease in scores for almost all cardinal symptoms of the GCSI and associated with significantly greater reductions in gastric retention with the help of ${ }^{13} \mathrm{C}-\mathrm{OBT}\left(T^{1} / 2\right.$ in dynamics - 112.2 $\left.1.1 \mathrm{~min} ; p<0.05\right)$ in patients of the second group, while in patients of the first group who received prokinetic itopride hydrochloride at a daily dose of $150.0 \mathrm{mg}$, the normalization of the function of the stomach after treatment was not observed ( $T^{1} / 2$ after treatment $\left.-84.4 \pm 8.4 \mathrm{~min} ; \mathrm{p}>0.05\right)$. There were no significant differences in fasting blood glucose levels between symptomatic therapy (Itopride hydrochloride) and laser acupuncture treatments.

\section{Discussion}

The obtained results indicated a high efficacy and safety of laser acupuncture sessions in combination with pathogenetic therapy agents, while no reliable result was achieved in patients with severe DG who received prokinetic itopride hydrochloride.

Perspectives for further research are to determine all possible pathogenetic mechanisms of reflexology action on the functional activity of the stomach, the gastrointestinal hormones, the central and autonomic nervous systems, as well as the state of carbohydrate and lipid metabolism in patients with DM.

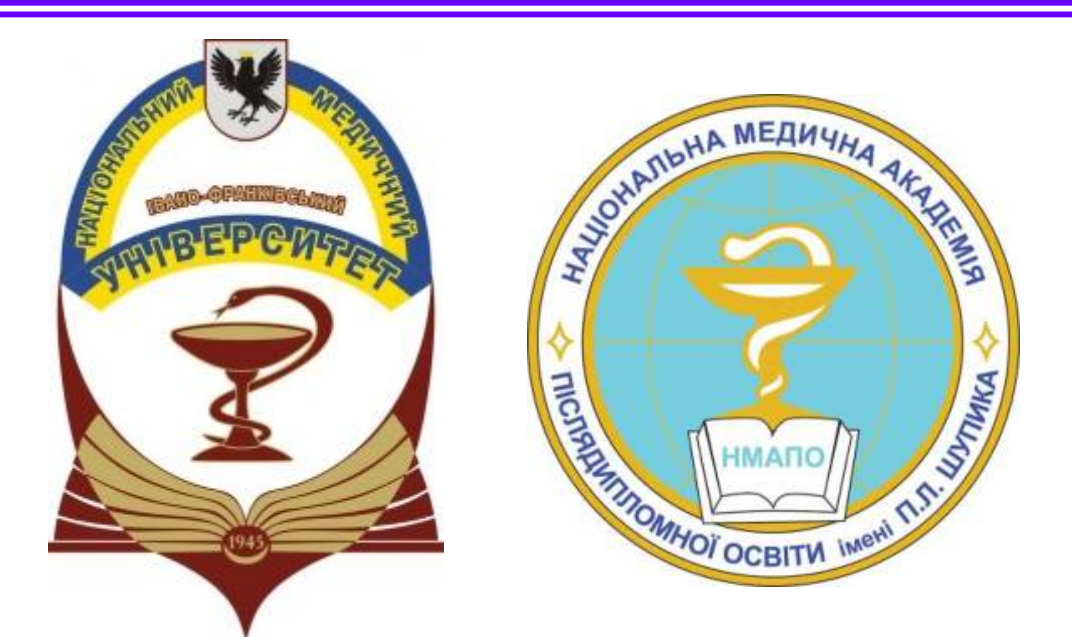

